\section{A COURSE OF LECTURES} ov

\section{DISEASES OF THE BRAIN INSANITY}

DELIVERED IN THE HOPITAL DE LA SALPETRIERE, PARIS,

By M. BAILLARGER,

PHYSICIAN TO THE LUNATIC DEPARTMENT IN THAT INSTITUTION.

(Furnished to 'THE LANcer' by the Lecturer, and Translated for that journal by RoBert Bannes, M.B., Lond., formerly a student at the Salpetrière.)

\section{LECTURE III}

Predisposing Causes.-Hereditary Transmission-continuation.

Third Question.-What is the proportion of cases of insanity due, wholly or in part, to the influence of hereditary transmission and of those which are, or appear to be, solely produced by accidental caúses?

THоse authors who have written upon mental alienation, especially since Esquirol, have nearly all put forth statistical tables of the causes of insanity, and in these tables the proportion of cases of hereditary insanity has always been noted. Unfortunately, if we bring together the results obtained, we find that they vary extremely, and the most superficial examination suffices to prove that these labours are utterly valueless in solving the question.

I deem it superfluous to cite in this place all the results that have been published: I confine myself to a reproduction of the principal ones.

\begin{tabular}{|c|c|c|c|}
\hline & $\begin{array}{c}\text { Number } \\
\text { of } \\
\text { patients } \\
\text { admitted. }\end{array}$ & $\left|\begin{array}{c}\text { Cases in which } \\
\text { the influence of } \\
\text { hereditary } \\
\text { transmission } \\
\text { was recognised }\end{array}\right|$ & Proportion. \\
\hline Establishment at Ivry (Esquirol) .. & 431 & 150 & 1 in 2.87 \\
\hline ", Charenton (Esquirol) & 1557 & 337 & 1 in 4.62 \\
\hline Turin (Bertolini) .... & 1066 & 128 & 1 in 8.32 \\
\hline Bicêtre (Desportes).. & 3458 & 342 & 1 in 10.11 \\
\hline
\end{tabular}

Other authors have found but 1 in 15 , or even 1 in 20 .

There is, in the outset, a fact which at once proves these results to be destitute of value. The cases in which the influence of hereditary transmission has been ascertained have been compared with the number of admissions; now among the patients admitted, there are many concerning whom either no information at all, or but very scanty particulars, could be obtained. These patients ought at once to be put aside; for as far as the question is affected, they might as well be disregarded.*

The first condition to fulfil, then, would be, to separate the patients concerning whom information is possessed, and those concerning whom none could be obtained. In proceeding as has been done, it results that in the case where particulars concerning the patients have been numerous, the proportion of instances of hereditary insanity is higher; that, on the contrary, under the opposite conditions it is lower.

Esquirol possessed information about nearly all his patients, because he only received, at his asylum at Ivry, individuals belonging to the upper classes of society; whence the very high proportion he has given.

Dr. Archambault, chief physician to the asylum at Maréville, found 60 cases of hereditary transmission out of 147 patients, or 1 in 2.45 ; but this physician informs us that he has actually obtained information concerning only 103 ; which gives a proportion of 1 in 1.70, that is, the highest proportion that any author has hitherto given.

The particulars obtained by M. Archambault were taken with care, which partly explains the results I have just cited; but it is easy to perceive that authors would have arrived at much higher proportions by patting aside those patients about whom they had collected no particulars.

* These observations are borne out by the recent "General Report of the Royal Hospital of Bethlehem, for the year ending the 31st December, 1844," Royal Hospital of Bethlehem, for the year ending the 31 st December, 1844,
from which it appears that out of 212 curable patients admitted during 1844, hereditary insanity was traced in 9 males and 17 females, ( 1 in 8.15 , ) while the remaining cases are all traced to accidental, moral, and physical causes. It is evident that no satisfactory conclusions can be arrived at from these Translator.

+ This admirable private asylum, founded by Esquirol, is now conducted by his successors, MM. Mitivié, Baillarger, and Moreau.-Translator. No. 1123.
Such is the principal reason which compels us to regardias beside the question the results above cited, but it is far from being the only one.

Before seeking to determine the proportion of cases of hereditary transmission, it was evidently indispensable accurately' to define in what cases the influence of hereditary transmission was to be admitted. When the father or the mother of a lunatic bas been afflicted with mental disease, we admit wholly, or in part, the influence of hereditary transmission as cause of the insamity. Upon this point all are agreed, but suppose-

1st. That the father and the mother have always been of sound mind, but that one or several of the brothers or sisters, an uncle, an aunt, a cousin, or a nephew only, have been affected with insanity. Will you admit in all these cases, or only in some of them, the influence of hereditary transmission? At what degree of relationship will you stop?

It is evident how indispensable it was to be well agreed upon this point, in order to have results that could be compared together. Suppose that one physician admits the hereditary transmission of insanity, only when the father or the mother or a brother has been insane; that, on the contrary, another physician is satisfied if he can ascertain the existence of the disease in an uncle or a cousin. It is obvious that the results obtained will differ in appearance only, on account of the manner in which the facts shall have been collected.

But these difficulties are not all

1st. I suppose that none of the relatives of the patient have been insane, but that his father has made himself remarkable by his eccentricity, or by very decided originality, or that he has been addicted to all kinds of excess; that throughout his life he has been conspicuous for the want of all moderation in his conduct; or that, again, he has been exceedingly weak-minded, and of no character at all; or that, on the contrary, he has been very violent and passionate, and that he has more than once, from insignificant motives, committed extremely serious acts of violence. Suppose even, that instead of finding some of these characteristics in the father or the mother, you were to meet them only in the grandfather or the grandmother, in a brother, a sister, an uncle, or an aunt, will you decide that in this case the insanity is owing to hereditary transmission?

2ndly. None of the relatives have been affected with insanity; none were eccentric, original, or weak-minded, or of violent character; but one or several have been subject to epilepsy, hysteria, or hypochondriasis. Will you say also, in this case, that the insanity is hereditary?

3rdly. Nothing of all that precedes has existed among the relatives, but the father has fallen, at an early age, into senile dementia; or the mother has, after confinement, been seized with a transient delirium of several days' duration, or with a cerebral fever. Will you take these facts into consideration when the question is to decide whether or not a particular case of insanity is due to hereditary transmission?

These questions, and others which I might here examine, have never been considered by authors, so that when they have said that they have met with hereditary transmission one time in three, in six, in ten, or fifteen, we really do not know what it is they wished to express.

Have they only reckoned those cases in which the father or the mother, the grandfather or the grandmother, had been insane; or have they reckoned those also in which only a brother or an uncle had been affected with insanity? And when meutal alienation has existed in none of the relatives, have they looked upon as satisfactory those cases in which one or several relations had merely manifested a degree of eccentricity, of weakness of mind, or various cerebral diseases different from insanity?

It is in the highest degree important to be perfectly agreed upon all these points ; for according as we restrict ourselves to such or such a category of facts, or admit them all, we shall arrive at very different results.

For these reasons I think that we are not called upon to accept the proportion of cases of hereditary transmission indicated by authors.

There is, besides, independently of the cases of insanity due to hereditary transmission, and those which are, or appear to be solely produced by accidental causes, a series of facts which it is necessary to isolate, and which is in a manner intermediate. I refer to those patients in whose families there has been found no trace of insanity, or any nervous disease; but who have themselves, for a long time prior to the outbreak of delirium, manifested symptoms of a well-marked predisposition-a predisposition which, according to the information obtained, we may look upon as congenital or acquired, but which is for the most part congenital.

In these individuals, we cannot say that the insanity is heredi- 
tary; but it would be equally erroneous to attribute it to accidental causes; for everything in the previous history of the patient reveals the predisposition to insanity and nervous diseases.

We see, then, how complicated the question, apparently so simple, of the determination of the hereditary transmission of insanity, really is. It becomes, therefore, indispensable to establish, in the first place, an uniform plan, upon which all researches on the hereditary transmission of insanity shall for the future be made. The following is what appears to me the most suitable method to be adopted in the classification of patients admitted into lunatic asylums, with reference to the influence of hereditary transmission.

\section{MEREDITARY INSANITY.}

1. Cases of insanity due wholly, or in part, to the influence of hereditary transmission.-1st. Cases in which one or several near relations (father, mother, paternal or maternal grandfather or grandmother, brothers or sisters, uncles or aunts) have been subject to insanity.

2nd. Traces of a predisposition to insanity in the relations.Patients in whose family there have been observed indications of a well-marked predisposition to insanity, (eccentricity, originality, violence of character, weakness of mind, ungovernable passions, excesses of all kinds.)

3rd. Nervous diseases in the relations.-Cases in which one or several relations have been subject to nervous diseases, (epilepsy, hysteria, hypochondriasis, delirium tremens, dementia senilis at an early age, cerebral fevers.)

2. Cases of insanity due to an anterior predisposition, congenital or acquired, but not hereditary.-(Symptoms of an anterior predisposition in the patient only.) No indication of insanity or of nervous diseases in the family, but well-marked signs of predisposition in the previous history of the patient himself; eccentricity, originality, violence of character, nervous diseases.

3. Patients in whom the insanity can, at least in appearance, be only attributed to accidental causes. - These are the cases in which it has not been possible to discover any indication of insanity or nervous disease in the family, or any trace of a predisposition, congenital or acquired, in the patient himself.

4. Doubtful cases.-(Cocisins, or nephews, or great uncles, having been insane.)

5. Patients concerning whom no information has been obtained.Thus, if, for example, it were desired to state the results obtained from a hundred patients, it might be done in the following manner:-

The figures, be it observed, are only approximative-

Cases of hereditary insanity ............. 40

Indications of insanity in the relations... 10

Nerrous diseases in the relations ......... 5

Cases of insanity due to the influence of

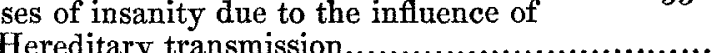

Predisposition, congenital or acquired

Accidental causes

Doubtful cases.

Doubtful cases ........................................
Cases without information concerning them ........

5
5
55

(n)

$\begin{array}{r}55 \\ 5 \\ 10 \\ 10 \\ 20 \\ \hline 100\end{array}$

It is, however, easy to conceive that statistics of this kind, with whatever care they may be drawn up, can never be perfectly exact, especially when we undertake to sum up those which have been made by different observers.

We may, indeed, shew ourselves more or less rigid in the appreciation of facts. One physician will turn over to the doubtful cases an observation which another will admit among those in which the influence of hereditary transmission has been proved. The manner of collecting information, the care and skill exercised in interrogating the relations of the patients, must also be taken into the account.

Lastly, there are sources of error which it is impossible to avoid. Sometimes the relations conceal the truth from the physician to whom they are giving information. Moreover, in some cases the influence of hereditary transmission can only be shewn, at a subsequent period, by the outbreak of insanity in one or several relations, and I shall hereafter cite several facts of this description.

As to seeking, at the present day, to determine the proportion of cases of insanity that are due to hereditary transmission, I believe it to be in vain. The documents collected are insufficient, and, moreover, marred by much inexactitude.

The proportion of one in 1.70 obtained by M. Archambault, is, in my opinion, still too low. This physician cansed printed sheets indicating the information required to be sent to the mayors of the communes in which the patients resided, and it is evident that many facts must escape registration.

The observations which I have hitherto collected induce me to believe that the proportion of cases due to hereditary transmission is at least three in four, if we take into consideration eccentricity and nervous diseases existing in one or several relations.

Hitherto, statistical researches on the hereditary transmission of insanity have only aimed at determining the proportion of cases of insanity due to the influence of hereditary transmission, and of those which apparently ought to be attributed to accidental causes. For this purpose, information has been collected with care concerning the ancestors and the collateral relations of the patients.

There is another question which has not been raised, the solution of which would be highly important with reference to the prognosis to be delivered concerning children born of insane parents.

It is to determine the number of cases in which the insanity continues to be hereditary, or becomes so. For this purpose it would be essential to have exact information concerning the children and grand-children of the patients.

I take the case of a hundred patients having one or several children: in how many cases will insanity declare itself in one or more of them? In other words, what are the chances of falling into insanity for the children born of insane parents. Does the insanity arising from accidental causes become hereditary, or is it only the insanity of those who owe their aftliction to hereditary influence, which can be transmitted to the children?

The solution of these questions, and of many others, is, at the present day, impossible, for waut of documents; but there can be no doubt that, in future inquiries, their solution should be sought.

Fourth question.-According to what conditions and what laws does hereditary transmission take place?

The study of hereditary diseases is so little advanced that the subject I am now examining is, as vet, extremely restricted. I have referred all I have to say upon this point to several questions which I shall successively consider. I shall begin with the three following, which appear to me to possess peculiar interest.

1. Is the insanity of the mother, other circumstances being alike, more frequently hereditary than that of the father?

2. In the cases of hereditary insanity, does the disease of the mother transmit itself to a greater number of children than that of the father?

3. Is insanity transmitted more frequently from the mother to the daughters, and from the father to the sons?

Out of the observations which I have collected, those which are available in the solution of these questions are six hundred in number. These six hundred observations, summed up in thirty-eight statistical tables, may be divided into three series.*

The first, the most numerous series, contains four hundred and forty cases, in which the insanity was transmitted in a direct line by the father or the mother.

The second contains only thirteen observations. The patients in these thirteen cases had had at the same time both collateral relations and brothers and sisters insane.

In the one hundred and forty-seven observations of the third series there had only been in the families of the patients collateral relations affected with insanity.

The influence of hereditary transmission cannot be called in question in the observations of the first and second series; it is not so in those of the third.

The insanity of one or several collateral relations is certainly not sufficient to establish that the disease is hereditary. No doubt, in the majority of these cases, the influence of hereditary transmission really exists; but it caunot be denied that many errors are possible, and these errors would be more than enough to affect results which, besides, are founded on numbers at present too small.

I have, therefore, thought it proper to discard the one hundred and forty-seven observations of the third series. There remain, then, four hundred and fifty-three cases, which will alone serve me in the examination of the three questions mooted above.

First question.-Is the insanity of the mother, cateris paribus, more frequently hereditary than that of the father?

I shall begin by admitting, what has been proved by very numerous statistical tables, that insanity is very nearly equally frequent in the two sexes, and that the proportion of insane married patients is the same in men as in women.

The source of hereditary insanity being the same for both sexes, it is evident that if we find more cases transmitted by the father or the mother, we can only attribute the fact to the greater facility with which the transmission takes place through one of the parents.

The researches published in France on the causes of insanity

* These thirty-eight tables have been addressed to the Royal Academy of Medicine, which body has deputed Professor Royer-Collard to report upen
them. 
contain, as far as I am aware, but one single document which can be of use in the solution of the question I am examining. I allude to the table drawn up by MM. Aubanel and Thore, in the service of $\mathbf{M}$. Ferrus, at Bicêtre. This table contains fourteen cases, in which it has been ascertained whether the disease was inherited from the father or from the mother. The insanity in these fourteen cases had been transmitted eight times by the father and six times by the mother.

The authors, however, whom I have just quoted, are careful not to conclude anything from so small a number of observations. They confine themselves to remarking, that this result is at variance with the opinion of Esquirol, who held that insanity was more frequently transmitted by the mother than by the father.

It is, I think, important to observe, that the table of M.M. Aubanel and Thore, even though it had included a greater number of patients, could not have served to the solution of the question. At the asylum of Bicêtre there are only insane males. What might be true for one sex alone might no longer be so for the two sexes taken together. In reality, we shall discover remarkable differences in this respect.

It is therefore essential for the solution of the question under examination, that the statistics shall include an equal number of males and of females.

The following are the results which $I$ have obtained:-Out of 453 lunatics affected with hereditary insanity, the disease had been transmitted by the mother 271 times, by the father 182 ,

The difference is $\overline{89}$, or about one-third.

The insanity of the mother is, therefore, more frequently hereditary than that of the father, in the proportion of one third.

Second question.-In the cases of hereditary transmission, does the disease of the mother transmit itself to a greater number of children than that of the father?

The result of the tables $I$ have made is the following:-

Out of 271 families in which the insanity had been transmitted by the mother, the disease, at the period when the observations were taken, had declared itself-

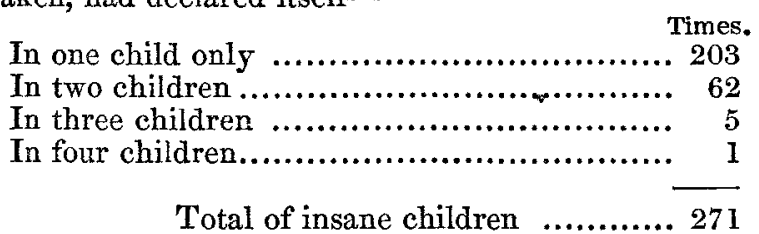

The insanity of the mother had therefore been transmitted to several children sixty-eight times out of 271 -that is to say, in one-fourth of the cases.

As to the insanity transmitted by the father, I have found-

That out of 182 families, in which the insanity was derived from the father, the disease had, at the time when the observations were taken, attacked-

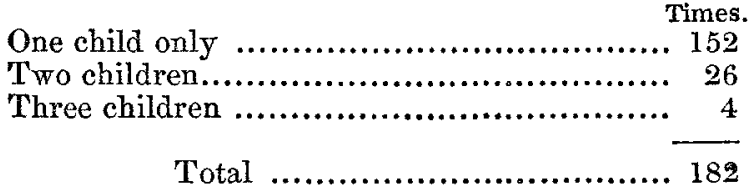

The insanity of the father was therefore transmitted to several children, thirty times out of 182-that is to say, in one-sixth of the cases.

Thus, the insanity of the mother, while it is more frequently hereditary than that of the father, appears also, cateris paribus, to reach a greater number of children.

Third question.-Is insanity more frequently transmitted from the mother to the daughters, and from the father to the sons?

Out of 346 children who had inherited the disease from the mother, I have found-

$$
\text { and } 197 \text { girls }\{346
$$

The difference is 48 , or one-fourth.

Out of 215 children, to whom the disease had been transmitted by the father, I have found-

$$
\left.\begin{array}{r}
128 \text { boys } \\
\text { and } 87 \text { girls }
\end{array}\right\} 215
$$

The difference is 41 , or one-third.

The insanity of the mother is transmitted, therefore, to the girls more frequently than to the boys, in the proportion of onefourth; the insanity of the father, on the other hand, to the boys more frequently than to the girls, in the proportion of one-third.

In comparing the results I have just stated, we perceive at once two other relations which appear to me not to be void of interest.

We find in reality, that out of 271 boys-

146 derived their insanity from the mother. 125 from the father.

The difference is 21 , or scarcely one-sixth.

For the girls, on the contrary, this difference is much more marked, and this is the result which seems to me to be the most interesting of all which precede.

Out of 274 insane girls-

189 derived their insanity from the mother. 85 only from the father.

The difference is 104-that is to say, more than one half.

Whence this conclusion, that boys derive their insanity about as often from the father as from the mother; but that the girls, on the contrary, inherit their insanity at least twice as often from the mother as from the father.

In making the application of the results I have obtained to the prognosis to be delivered upon ehildren born of insane parents, we arrive at the following conclusions :-

1. The insanity of the mother, with regard to hereditary transmission, is more serious than that of the father, not only because it is more frequently hereditary, but also because it transmits itself to a greater number of children.

2. The transmission of the insanity of the mother is more to be apprehended in the girls than in the boys; that of the father, on the contrary, is more to be apprehended in the boys than in the girls.

3. The transmission of the insanity of the mother is scarcely more to be apprehended in the boys than in the girls; it is, on the contrary, twice as much to be apprehended in the girls.

Before concluding, I ought to add, that I am far from pretending that the six hundred observations summed up in the tables addressed to the Academy, are sufficient for the complete solution of the questions I have stated. On the contrary, I simply look upon them as the first element of an investigation which ought to be continued.

Researches of this nature, apart from the study of insanity, are interesting to physiology, and the history of hereditary diseases in general, as yet so little advanced.

These researches must therefore, for the future, be persevered in; and lunatic asylums offer in this respect facts so numerous, that in the course of a few years we cannot avoid arriving at definite results.

Physiological Applications.-How far may we extend the application of these results to physiology?

The transmission of the predisposition to insanity is evidently, at least in part, the result of the transmission of a certain cerebral organization. Now, since the girls, for example, cateris paribus, inherit this abnormal organization twice as often from the mother as from the father, may we conclude that the same relation exists in the physiological state for the transmission of the intellectual and moral faculties?

In drawing this conclusion, I should only be following the example of those authors who have treated questions of this nature.

Thus, when Burdach seeks to prove that, according to the popular opinion, the girls inherit more frequently from the father, and the boys from the mother, he cites, especially, examples of anomalous organization transmitted exclusively from the mother to the boys, and from the father to the daughters.

Such are the applications which the preceding researches might supply to physiology, if more numerous observations shall hereafter come to confirm the results I have obtained.

We might admit, generally, that children, as far as regards the intellectual and moral faculties, take more frequently after the mother than the father.

Burdach calls to mind that this opinion is so popular in Germany and some other countries, that there exists in the language a particular word, which signifies maternal wit.*

It has often been remarked that superior men have sprung from women remarkable for intellectual development. Sinclair instances several women of superior mind who have quickened the intellectual faculties in those families with which they have

* Mutterwitz, Anglicè, Motherwit. It may, however, fairly be questioned whether this word owes its oripin to the popular opinion alluded to by Burdach or to that inherent tendency in the human mind which makes by Burdach or to that inherent tendency in the human mind which makes us more disposed to associate all ideas of generation with a maternal, rather than with a paternal principle. Thus, among the ancients, the Earth was the mother of all things; and in every case in which the intellectual faculty is concerned, the generative principle is 
become allied; and he attributes, among other examples, to a woman the talents which distinguished the family of the Pitts.

Burdach, from whom I borrow these details, adduces, in addition, the opinion of Fabricius, who had observed that gout and cachexies were inherited from the father; spasms, melancholy, vivacity, and the intellectual faculties, from the mother.

I believe that the more frequent transmission of insanity by the mother than by the father will be, henceforth, an additional argument in favour of all these facts.

There is another opinion still more general than the preceding, but to which the results $I$ have obtained are altogether opposed.

It is said that boys take more frequently after the mother, and the girls, on the contrary, more frequently after the father; and that there is thus a kind of reciprocation between the sexes.

Science possesses no precise materials, at least with regard to the human race, which can have served to the solution of this question. Whence it is remarkable with what indecision physiologists have explained themselves upon this point.

Boys, says Haller, often take after the mother; girls often after the father. Burdach, as I have said above, while citing pathological facts in support of this sort of reciprocation of the sexes, appears also to remain in doubt.

"The popular opinion that the girls generally resemble the father, say MM. Richerand and Berrard, while the male children more frequently bear the features of their mother, bears upon too great a number of facts for it to be possible to look upon it as altogether false. Is this the reason, they add, for which so many men illustrious for their genias, and for their numerous successes in science and literature, have transmitted their name to sons incapable of maintaining its renown?"

Thus the question has never been clearly decided, nor could it be so, for the numerous facts appealed to are, so to speak, everywhere and nowhere: no one has brought them together or counted them.

The researches on the hereditary transmission of insanity appear, in this respect, altogether adverse to the popular opinion of the reciprocation of the sexes in generation. So far from this pretended reciprocation being the more general fact, it is the very opposite we ought to admit. 'These researches tend, in reality, to bear out the conclusions, that the transmission of the intellectual and moral faculties is much more frequent from the mother to the daughters, than from the mother to the sons; that this transmission, on the contrary, takes place much more frequently from the father to the sons than from the father to the daughters.

I would especially call to mind the result, so clearly marked, that out of two hundred and seventy-four girls, eighty-five had inherited the insanity from the father, and one hundred and eighty-nine-that is to say, more than two-thirds-derived this disease from their mother.

APPLICATIONS TO THE GENERAL HISTORY OF HEREDITARY DISEASES.

In whatever mauner the importance of statistical researches on the hereditary transmission of insanity may be regarded with reference to physiology, it is impossible not to recognise their importance with respect to the general bistory of hereditary diseases. This history is, in reality, but little advanced. I can give no better proof of this, than the almost complete absence of documents adapted to the solution of the questions I have examined.

Thus, in taking, for example, the most common disease, what precise knowledge do we possess concerning the hereditary transmission of phthisis? M. Louis has not started the questions which I have raised, and the statistics published by MM. Piorry and Briquet contain, the one only forty-nine patients, and the other only twenty-nine. The results arrived at are not in harmony. According to the figures of $\mathbf{M}$. Piorry, phthisis is derived more frequently from the mother, and according to those of M. Briquet, more frequently from the father. There are still fewer accurate documents for gout, scrofula, \&c.

I feel called upon to direct attention to the fact, that the study of insanity can, better than that of any other disease, conduce to the advancement of the general history of hereditary transmission, and to the determination of the laws it follows.

The phthisical, the scrofulous, the gouty, are scattered here and there, and a single observer could only succeed, by a great sacrifice of time and trouble, in collecting a sufficient number of observations. The insane, on the contrary, are drawn together by hundreds in the asylums; thus, at the Salpétrière and at Bicêtre there are more than 2000 lunatics, and nothing is more easy than in a few years to collect very numerous observations.

There is another consideration not less important. It is far easier to determine whether the relations of a patient have died insane, than to ascertain if they have suceumbed to phthisis scrofula, or gout.

Hence it is that the study of insanity can, better than that of any other affection, facilitate the solution of various problems belonging to the general history of hereditary diseases; and I have thought the preceding statistical researches might possess some interest in this respect.

I have said that I was far from regarding the solutions of the questions I have examined as settled; that I considered, on the contrary, the documents above cited as the first element of a work which it was necessary to carry on. With this view, I have had tables printed, the model of which I subjoin.

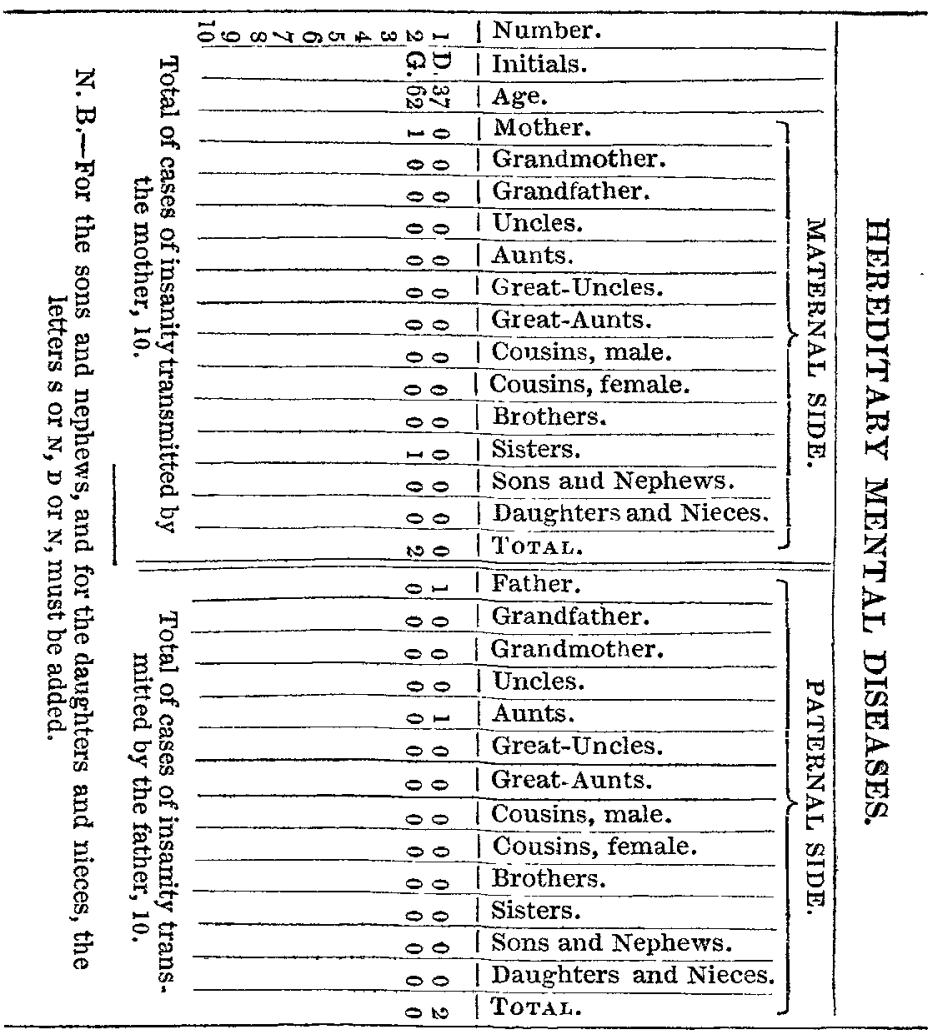

Each of these tables will contain ten observations of hereditary mental diseases. Some will serve for the cases of hereditary transmission in insane females, others for those observed in male patients.

When I shall have collected from 500 to 600 fresh observations, I shall again aualyze them. It is evident, indeed, that in questions of this nature the truth can only be elicited from a great number of facts.

\author{
ON THE
}

RISE, PROGRESS, AND MYSTERIES

MESMERISM

IN ALI AGES AND COUNTRIES.

By CHARLES RADCLYFFE HALL, M.D.

CXTRA-LICENTIATE OF THE COLLEGE OF PHYSICIANS, LONDON.

No. IV.

The Facts of Modern Mesmerism-continued.

EFFECTS STATED TO HAVE BEEN PRODUCED BY MESMERIC OPERATIONS.

\$218. Miscellaneous Effects.-The first effect is a look of stupor in the ege, and a lack of power to wink; the eye closes. Long after this, the hearing retains all its acuteness; after the patient is deaf to every sound save that of the mesmeriser's voice, he is still alive to feeling. The usual sign of the patient having passed into the mesmeric state is, that the head of the patient will follow every motion of the mesmeriser's hand.

\$219. Malle. M- is asked whether she is asleep. She replies, softly but distinetly, "Oui, je dors." On one of the party expressing a doubt of the fact, she exclaims, "Yes, certainly, I am asleep." A Belgian gentleman in the mesmeric state, mentions when he is asleep, and when he wishes to be awoke.

$\S 220$. A gentleman, at Cambridge, whilst in the mesmeric 